\title{
Overexpression of long noncoding RNA PEG10 promotes proliferation, invasion and metastasis of hypopharyngeal squamous cell carcinoma
}

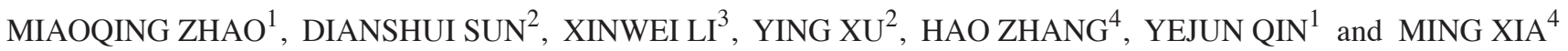 \\ ${ }^{1}$ Department of Pathology, Provincial Hospital Affiliated to Shandong University, Jinan, Shandong 250021; ${ }^{2}$ Cancer Center, \\ The Second Hospital of Shandong University, Jinan, Shandong 250033; ${ }^{3}$ Institute of Environmental and Occupational Health, \\ Jinan Center for Disease Control and Prevention, Jinan, Shandong 250021; ${ }^{4}$ Department of Otorhinolaryngology \\ and Head and Neck Surgery, The Second Hospital of Shandong University, Jinan, Shandong 250033, P.R. China
}

Received October 31, 2015; Accepted April 21, 2017

DOI: $10.3892 / \mathrm{ol} .2017 .6498$

\begin{abstract}
The present study aimed to investigate the impact of overexpression of long noncoding RNA PEG10 (lncRNA PEG10) on the proliferation, invasion and metastasis of hypopharyngeal squamous cell carcinoma (HSCC). Quantitative reverse transcription polymerase chain reaction was used to quantify lncRNA PEG10 expression levels in HSCC tumor tissues samples, para-carcinoma tissue samples and the HSCC FaDu cell line. Cell proliferation assays, Transwell invasion assays and wound healing assays were used to evaluate the effects of 1ncRNA PEG10 on FaDu cells in vitro. In 56 eligible patients, lncRNA PEG10 was expressed at higher levels in HSCC tumor tissues compared with para-carcinoma tissues, and significant associations were observed between increased tumor expression of lncRNA PEG10 and primary tumor size, lymph node status and tumor node metastasis stage. In the in vitro experimental studies, enhanced expression of lncRNA PEG10 was significantly associated with increased proliferation, invasion and metastasis of FaDu cells. lncRNA PEG10 was upregulated in HSCC, and its overexpression in HSCC cells promoted an increase in the tumorigenic activities of proliferation, invasion and migration. The potential underlying mechanisms require investigation in future studies.
\end{abstract}

\section{Introduction}

Hypopharyngeal squamous cell carcinoma (HSCC) is one of the most common types of aggressive head and neck

Correspondence to: Dr Ming Xia, Department of Otorhinolaryngology and Head and Neck Surgery, The Second Hospital of Shandong University, 247 Beiyuan Avenue, Jinan, Shandong 250033, P.R. China

E-mail: xiamingsdu@sohu.com

Key words: long noncoding RNA, hypopharyngeal squamous cell carcinoma, proliferation, invasion, metastasis malignancy, with an incidence of $\sim 10$ cases/million people annually (1). A total of $>75 \%$ of patients with HSCC have an advanced stage of the disease at the time of diagnosis (2), and the prognosis of these patients is poor with a 5-year overall survival rate of $30-35 \%$ (3-5). The poor prognosis and frequently advanced stage at diagnosis are typically attributed to the local aggressiveness of the tumor, which exhibits a propensity for submucosal spread, invasion into adjacent structure and metastasis due to abundant lymphatic drainage $(6,7)$. These events are regulated by numerous key molecular oncogenic pathways. Therefore, understanding these pathways in HSCC may assist in understanding the biological characteristics of the tumor, and lead to novel insights to the search for improved disease therapy and preventative strategies.

Long noncoding RNAs (lncRNAs) are a novel class of RNA molecules defined as transcripts of $>200$ nucleotides (nt) that lack protein coding potential. They are typically transcribed by RNA polymerase II, but possess no open reading frame and map to intronic and intergenic regions. Additionally, lncRNAs demonstrate epigenetic characteristics that are similar to protein-coding genes (8). It has been estimated that $\sim 15,000$ lncRNAs are present in the human genome (9). Previous studies have demonstrated that lncRNAs may function as oncogenes or tumor suppressors in the cancer initiatome (10), serve important roles in carcinogenesis and cancer proliferation, invasion and metastasis, and correlate with cancer prognosis $(11,12)$. Therefore, 1 ncRNAs are a potential novel class of cancer biomarkers (13).

The present study focuses on IncRNA paternally expressed 10 (PEG10; NONCODE Gene ID NONHSAG048235), which is located on human chromosome 7 between the 94285681 and 94298949 base sites and is 763 bp in length (14). It was demonstrated that aberrant expression of PEG10 is associated with a number of malignancies, including hepatocellular carcinoma (15), B-cell lymphocytic leukemia (16), lymphoma (17) and esophageal cancer (18). With respect to esophageal cancer, it was identified that PEG10 regulates proliferation and invasion of esophageal cancer cells (18). In addition, studies have revealed that PEG10 is highly conserved across mammalian species, and serves an important role in cell proliferation, 
differentiation and metastasis $(10,19)$. However, the potential role of PEG10 in human hypopharyngeal carcinoma remains to be elucidated. Therefore, the aim of the present study was to investigate the role of PEG10 in HSCC.

\section{Materials and methods}

Patient selection and tissue sample collection. Patients who underwent curable surgery for hypopharyngeal carcinoma between January 2010 and October 2014 were screened, and cases, in accordance with the following criteria, were selected for the study: i) Diagnosis of HSCC was confirmed by postoperative pathological results; ii) patient did not receive chemotherapy or radiotherapy prior to surgery; iii) patient presented with local disease without any distant metastases at the time of diagnosis, and the tumor was resectable; iv) complete tumor resection was described in the surgical record with expected disease-free survival of $\geq 3$ months; v) patient received standard surgery for hypopharyngeal carcinoma, namely, primary tumor resection with lymph node dissection, and surgical margins were microscopically negative with no residual tumor; and vi) clinicopathological information (sex, age, tumor location, lymph node metastasis, differentiation and classification) was available.

For every eligible patient, primary tumor tissue and para-carcinoma tissue samples were immediately collected and frozen in liquid nitrogen following resection and stored at $-80^{\circ} \mathrm{C}$ until RNA extraction. Para-carcinoma tissue was defined as normal tissue adjacent to the primary tumor without any microscopic invasion.

All patients were from the Second Hospital of Shandong University and the Provincial Hospital Affiliated to Shandong University (Jinan, China). Written informed consent was obtained from all patients prior to participation in the study. The medical ethics committee of the Second Hospital of Shandong University and the Shandong Provincial Hospital approved the present study.

$R N A$ extraction and reverse transcription quantitative polymerase chain reaction ( $R T-q P C R)$ assay. For all eligible patients, total RNA was extracted from frozen primary tumor and para-carcinoma tissue samples. Total RNA was extracted and purified with the RecoverA11 ${ }^{\mathrm{TM}}$ Total Nucleic Acid Isolation kit (Thermo Fisher Scientific, Inc., Waltham, MA, USA). To ensure that total RNA fulfilled the requirements for the qPCR, the purity and quantity of RNA for each sample were analyzed (a minimum A260/A280 ratio of $>1.8$ was applied for all samples) and RNA integrity was assessed by formaldehyde-modified gel electrophoresis. Reverse transcription reactions were performed using $2 \mu \mathrm{g}$ total RNA, lncRNA PEG10 reverse transcription primer (Invitrogen; Thermo Fisher Scientific, Inc.), 5X first-strand buffer (Thermo Fisher Scientific, Inc.), 0.1 M DTT (Thermo Fisher Scientific, Inc.), a dNTP mixture (Takara, Bio, Inc., Otsu, Japan), Moloney Murine Leukemia Virus reverse transcriptase (Thermo Fisher Scientific, Inc.) and recombinant RNasin ${ }^{\circledR}$ RNase inhibitor (Promega Corporation, Madison, WI, USA). Following reverse transcription, qPCR reactions were performed using a 7900 HT Fast RealTime PCR system (Applied Biosystems; Thermo Fisher Scientific, Inc.) according to the manufacturer's protocol. Dissociation curve analysis was performed to assess the specificity of the amplified product. GAPDH was used as an internal control by comparing its expression levels in each of the specimens. Finally, 1.5\% non-denaturing agarose gel electrophoresis using $4 \mu \mathrm{l} \mathrm{qPCR}$ products was used to evaluate their quantity and specificity.

The thermocycler conditions for the RT-qPCR were as follows: 10 min denaturation at $95^{\circ} \mathrm{C}$, followed by 40 cycles of $95^{\circ} \mathrm{C}$ for $15 \mathrm{sec}$, and $60^{\circ} \mathrm{C}$ for $1 \mathrm{~min}$. SYBR-Green was used as the fluorophore. The method of quantification used for the qPCR was $2^{-\Delta \Delta \mathrm{Cq}}$ method (20) and the results were replicated three times.

The following primer sequences were used: lncRNA PEG10 primer sequence: Forward, 5'-CATCCTTCCTGTCTT CGC-3'; reverse, 5'-CCCTCTTCCACTCCTTCTTT-3'; probe, 5'-Fam-CCGCTTATTTCACGCGAGGA-Tamra-3'; GAPDH primer sequence: Forward, 5'-TGGTATCGTGGAAGGACT CA-3'; reverse, 5'-CCAGTAGAGGCAGGGATGAT-3'; Probe, 5'-Fam-CGCCACAGTTTCCCGGAGG-Tamra-3'. All primers were synthesized by Invitrogen (Thermo Fisher Scientific, Inc.).

Cell culture and transfection. The HSCC FaDu cell line was obtained from Shanghai Institutes for Biological Science (Shanghai, China). FaDu cells were cultured in RPMI-1640 medium (Nanjing KeyGen Biotech Co., Ltd., Nanjing, China) supplemented with $10 \%$ fetal bovine serum (FBS; Invitrogen; Thermo Fisher Scientific, Inc.) All cells were cultured at $37^{\circ} \mathrm{C}$ in a humidified atmosphere containing $5 \% \mathrm{CO}_{2}$.

In order to obtain high expression of lncRNA PEG10, FaDu cells were transfected with lncRNA PEG10. Small interfering RNA (siRNA) against lncRNA PEG10 were also designed and transfected to inhibit lncRNA PEG10 expression. Transfection was performed using Lipofectamine $2000^{\circledR}$ (Invitrogen; Thermo Fisher Scientific, Inc.) according to the manufacturer's protocol. The experimental groups included FaDu cells transfected with IncRNA PEG10 (PEG10+), cells transfected with silencer (si) lncRNA (si-lnc) and the negative control cells (NC) transfected with a nonsense siRNA control sequence. Transfection efficiency was measured in each experimental group 5 times using RT-qPCR analysis.

Cell proliferation assay. The Cell Counting kit-8 (CCK-8; Dojindo Molecular Technologies, Inc., Kumamoto, Japan) was used to evaluate the proliferative activity of FaDu cells according to the manufacturer's protocol. Following transfection, cells from each experimental group were seeded into 96-well plates at a density of $1 \times 10^{4}$ cells/well, with 5 replicate wells/group. The absorbance value for each well was determined using CCK-8. The optical density (OD) value represented the proliferation of FaDu cells and was measured daily over 4 consecutive days at a wavelength of $450 \mathrm{~nm}$ (OD450) to estimate the number of viable cells.

Transwell invasion assay. Transwell invasion assays were used to evaluate invasive activity of $\mathrm{FaDu}$ cells and were performed using a 24-well chamber containing Matrigel (3.9 $\mu \mathrm{g} / \mu \mathrm{l}, 60-80 \mu \mathrm{l})$-coated membranes with a pore size of $8 \mu \mathrm{m}$ (Costar; Corning Incorporated, Corning, NY, USA). Experimental group cells and the control cells were collected 
Table I. Association of lncRNA PEG10 expression with clinicopathological characteristics.

\begin{tabular}{|c|c|c|c|}
\hline $\begin{array}{l}\text { Clinicopathological } \\
\text { characteristics }\end{array}$ & $\mathrm{n}$ & $\begin{array}{c}\text { lncRNA PEG10 } \\
\text { expression }\left(2^{-\Delta \Delta \text { Cq }} \text { values }\right)^{\mathrm{a}}\end{array}$ & P-value \\
\hline Patient number & 56 & & \\
\hline Age, years & & & 0.3580 \\
\hline$\leq 60$ & 32 & $3.2725 \pm 1.2293$ & \\
\hline$>60$ & 24 & $3.5850 \pm 1.2734$ & \\
\hline Sex & & & 0.1219 \\
\hline Male & 40 & $3.2430 \pm 1.2221$ & \\
\hline Female & 16 & $3.8150 \pm 1.2514$ & \\
\hline Primary tumor site & & & 0.9938 \\
\hline Pyriform sinuses & 39 & $3.3967 \pm 1.3083$ & \\
\hline Posterior and lateral hypo-pharyngeal walls & 13 & $3.4169 \pm 1.1604$ & \\
\hline Postcricoid area & 4 & $3.4675 \pm 1.1915$ & \\
\hline Pathological differentiation & & & 0.4564 \\
\hline Well-differentiated & 12 & $3.0208 \pm 1.1527$ & \\
\hline Moderately differentiated & 19 & $3.5931 \pm 1.1285$ & \\
\hline Poorly differentiated & 25 & $3.4496 \pm 1.3761$ & \\
\hline Primary tumor size & & & 0.0174 \\
\hline $\mathrm{T} 1$ & 13 & $2.8131 \pm 1.0142$ & \\
\hline $\mathrm{T} 2$ & 23 & $3.2330 \pm 1.1519$ & \\
\hline T3 & 20 & $3.9915 \pm 1.2943$ & \\
\hline Lymph node status & & & 0.0002 \\
\hline No & 19 & $2.5774 \pm 0.9506$ & \\
\hline $\mathrm{N}+$ & 37 & $3.8322 \pm 1.1720$ & \\
\hline Clinical staging (Tumor node metastasis) & & & $<0.0000$ \\
\hline $\mathrm{I} / \mathrm{II}$ & 13 & $2.2100 \pm 0.7106$ & \\
\hline III & 15 & $3.2920 \pm 0.7290$ & \\
\hline IV & 28 & $4.0232 \pm 1.2550$ & \\
\hline
\end{tabular}

${ }^{\text {aD }}$ ata are presented as the mean \pm standard deviation.

and resuspended in serum-free medium at a concentration of $2 \times 10^{5}$ cells $/ \mathrm{ml}$. Cell suspensions $(200 \mu \mathrm{l})$ were added to the upper chamber, the bottom chamber was filled with $500 \mu \mathrm{l}$ of culture medium containing $10 \% \mathrm{FBS}$ and cells were incubated for $48 \mathrm{~h}$ at $37^{\circ} \mathrm{C}$ with $5 \% \mathrm{CO}_{2}$. A total of 5 wells were used for each group. Following incubation, the medium and stationary cells on the upper membrane surface were removed with a cotton tip and the cells that had passed through the filter were fixed in methanol, stained with $0.1 \%$ crystal violet for $10 \mathrm{~min}$, mounted and dried at $80^{\circ} \mathrm{C}$ for $30 \mathrm{~min}$. The number of cells invading the Matrigel was counted in 3 randomly selected fields using an inverted microscope at magnification, x200. The experiment was repeated 5 times.

Wound healing assay. Wound healing assays were performed to evaluate the migration activity of FaDu cells. Then, $5 \times 10^{5}$ cells $/ \mathrm{ml}$ cells from each experimental group were seeded on 6-well plates and cultured in RPMI-1640 medium supplemented with $10 \%$ FBS for $24 \mathrm{~h}$ to form a confluent monolayer cell. An artificial scratch wound on each confluent monolayer was created with a $10-\mu 1$ pipette tip. Serum-free medium was added for an additional $24 \mathrm{~h}$ incubation, and images of the cells were captured at 4 different time points $(0,24,36$ and $48 \mathrm{~h}$ ) using an inverted microscope at magnification, $\mathrm{x} 200$. The distance between the borders of the wounded region lacking cells was measured, and the relative migration ratio was calculated at each time point with 5 replicates/group.

Statistical analysis. The expression level of lncRNA PEG10 in each experimental group was calculated as mean \pm standard deviation. The differences between expression levels of lncRNA PEG10 were analyzed with paired sample t-tests, independent sample t-tests or one-way analysis of variance (ANOVA) with the Bonferroni test used as the post-hoc test. Statistical analyses were performed using the SPSS statistical software program (SPSS v17.0, SPSS Inc., Chicago, IL, USA). P<0.05 was considered to indicate a statistically significant difference.

\section{Results}

Eligible patient clinicopathological characteristics and association with the expression of IncRNA PEG10. Following the 


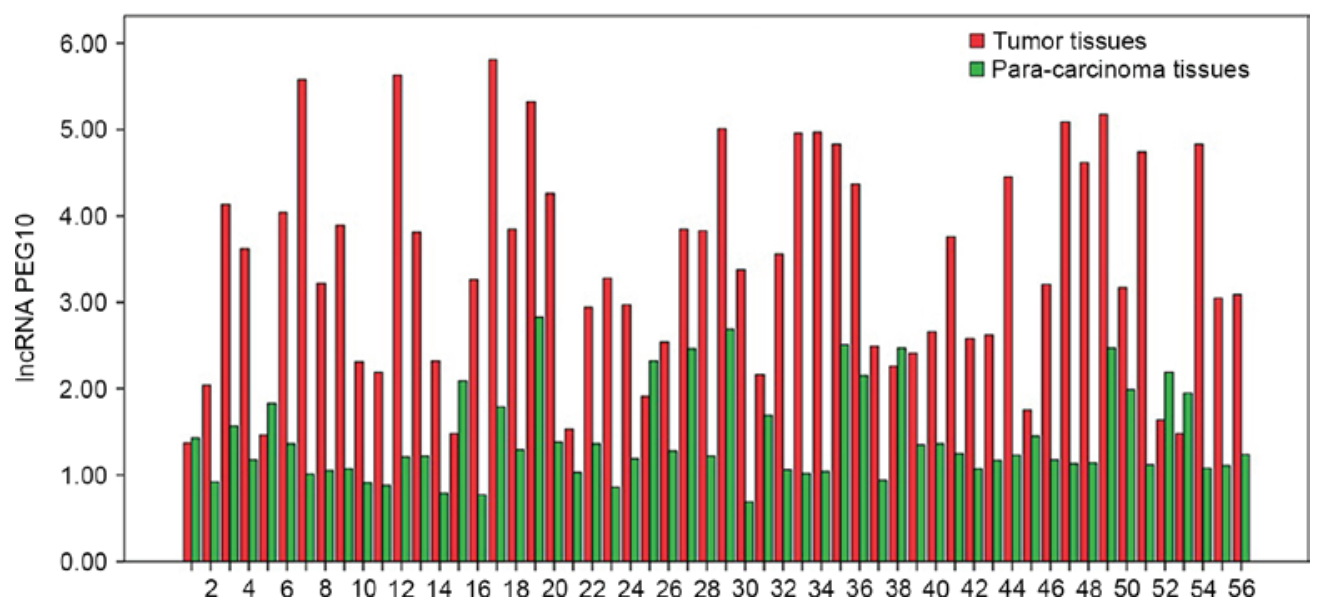

Figure 1. IncRNA PEG10 expression levels in HSCC tumor tissues and para-carcinoma tissues were presented as $2^{-\Delta \triangle C t}$ values. The expression level of lncRNA PEG10 was significantly upregulated in HSCC tumor tissues $(\mathrm{P}<0.05)$. lncRNA, long noncoding RNA; HSCC, hypopharyngeal squamous cell carcinoma; PEG10, paternally expressed 10.

inclusion criteria, 56 patients were eligible for the present study. The eligible patients included 40 males and 16 females, with a median age of 59 years (range, 47-76). The post-operation stage was defined according to the 8th edition American Joint Committee on Cancer (AJCC) classification system (21). All patient characteristics are summarized in Table I.

The expression levels of lncRNA PEG10 in tumor tissues and para-carcinoma tissues, presented as $2^{-\Delta \Delta \mathrm{Cq}}$ values, were $3.406 \pm 1.247$ and $1.429 \pm 0.544$, respectively $(\mathrm{P}<0.05$; Fig. 1$)$. The associations between the expression of 1ncRNA PEG10 in tumor tissues and clinicopathological characteristics of patients with HSCC were also analyzed. The results demonstrated that primary tumor size, lymph node status and Tumor node metastasis (TNM) stage were significantly associated with an increased expression of IncRNA PEG10 $(\mathrm{P}<0.05$; Table I). By contrast, there were no significant associations observed between lncRNA PEG10 expression and age, sex, primary tumor site or pathological differentiation (Table I). Based on these results, additional experimental studies with lncRNA PEG10 were performed to determine its role in HSCC pathogenesis.

Expression profile of IncRNA PEG10 in transfected FaDu cells. Expression levels of IncRNA PEG10 were examined using RT-qPCR in FaDu cells transfected with lncRNA PEG10 (PEG10+), negative control RNA (NC) or silencer lncRNA PEG10 (si-lnc). Expression levels quantified as $2^{-\Delta \Delta \mathrm{Cq}}$ values were $2.448 \pm 0.440,1.762 \pm 0.280$ and $0.552 \pm 0.209$ in PEG10+, $\mathrm{NC}$ and si-lnc groups, respectively (Fig. 2). Differences among groups were identified to be significantly different using one-way ANOVA analysis $(\mathrm{P}<0.05)$. Post-hoc testing demonstrated that IncRNA PEG10 expression was significantly reduced in cells transfected with silencer si-lnc RNA compared with PEG10+ and NC cells $(\mathrm{P}<0.05)$, while IncRNA PEG10 expression was enhanced in PEG10+ cells compared with NC cells $(\mathrm{P}<0.05)$.

IncRNA PEG10 promotes cell proliferation. The alterations in IncRNA PEG10 expression in transfected FaDu cells were associated with alterations in proliferative capacity.
Mean $\mathrm{OD}_{450}$ values from replicate cell proliferation assays of PEG10+, NC and si-lnc cells, respectively, were as follows: $24 \mathrm{~h}: 0.496 \pm 0.075,0.384 \pm 0.035$ and $0.260 \pm 0.052 ; 48 \mathrm{~h}$ : $0.892 \pm 0.033,0.672 \pm 0.046$ and $0.428 \pm 0.080 ; 72 \mathrm{~h}: 1.124 \pm 0.101$, $0.900 \pm 0.073$ and $0.560 \pm 0.037 ; 96$ h: $1.308 \pm 0.101,1.054 \pm 0.102$ and $0.752 \pm 0.056$. The cell growth curves are demonstrated in Fig. 3. Proliferation values for the PEG10+ group were significantly increased compared with those of the NC group at all time points $(\mathrm{P}<0.05)$, while values for the si-lnc group were significantly decreased at the identical time points compared with the PEG10+ and NC groups $(\mathrm{P}<0.05)$. These results indicate that overexpression of lncRNA PEG10 promoted in vitro proliferation of FaDu cells.

lncRNA PEG10 promotes cell invasion. In Transwell assays, the means of cell numbers penetrating the membranes in the PEG10+, NC and si-lnc groups were $1.408 \pm 0.099 \times 10^{5}$, $0.988 \pm 0.092 \times 10^{5}$ and $0.672 \pm 0.081 \times 10^{5}$, respectively. The number of invading cells was significantly higher in the PEG10+ group compared with the NC group ( $\mathrm{P}<0.05$; Fig. 4). By contrast, the number of invading cells in the si-lnc group was significantly lower compared with the that in the PEG10+ and NC groups $(\mathrm{P}<0.05$; Fig. 4). These results indicate that the overexpression of 1ncRNA PEG10 increased the invasive capacity of FaDu cells in vitro.

lncRNA PEG10 promotes cell migration. Finally, cell migration in transfected $\mathrm{FaDu}$ cells was examined using wound healing assays. The mean relative migration ratios for cells in the PEG10+, NC and si-lnc groups, respectively, were as follows: $24 \mathrm{~h}$ : $0.514 \pm 0.045,0.356 \pm 0.036$ and $0.320 \pm 0.047$; $36 \mathrm{~h}: 0.808 \pm 0.041,0.652 \pm 0.051$ and $0.552 \pm 0.054 ; 48 \mathrm{~h}$ : $0.952 \pm 0.031,0.830 \pm 0.036$ and $0.698 \pm 0.038$. The relative migration ratio of FaDu cells in the PEG10+ group was significantly increased compared with the ratios in the $\mathrm{NC}$ and si-lnc groups at each time point $(\mathrm{P}<0.05$; Fig. 5). Similarly, the relative migration ratio of FaDu cells in the NC group was significantly increased compared with the ratio in the si-lnc group at 36 and $48 \mathrm{~h}(\mathrm{P}<0.05$; Fig. 5), but the difference was not significant at $24 \mathrm{~h}$. These results suggest that 


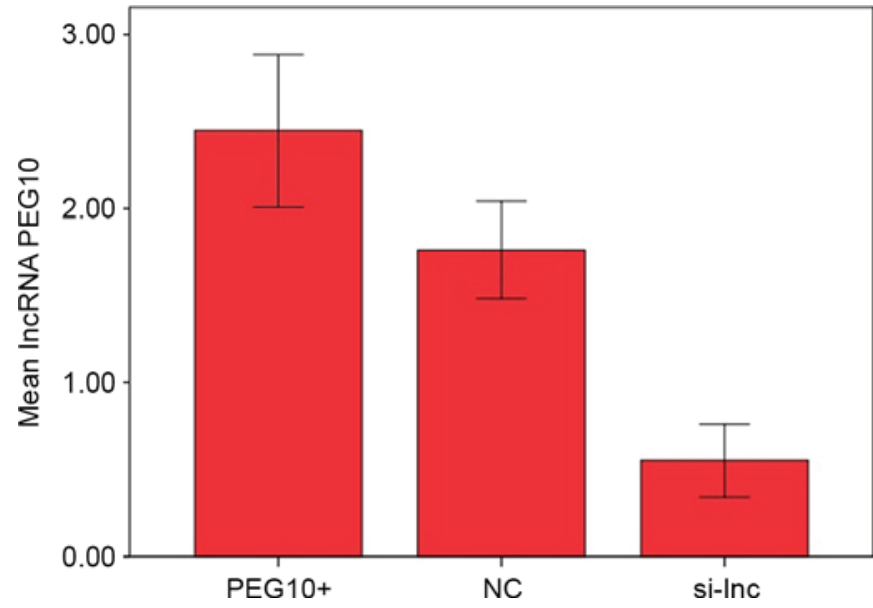

Figure 2. 1ncRNA PEG10 expression levels in the 3 experimental groups of $\mathrm{FaDu}$ cells were presented as $2^{-\Delta \Delta \mathrm{Ct}}$ values. IncRNA PEG10 expression was significantly reduced in cells transfected with silencer si-lncRNA compared with PEG10+ and NC cells $(\mathrm{P}<0.05)$, while lncRNA PEG10 expression was enhanced in PEG10+ cells compared with NC cells $(\mathrm{P}<0.05)$. IncRNA, long noncoding RNA; PEG10, paternally expressed 10; si-lnc, silencer lncRNA; $\mathrm{NC}$, negative control.

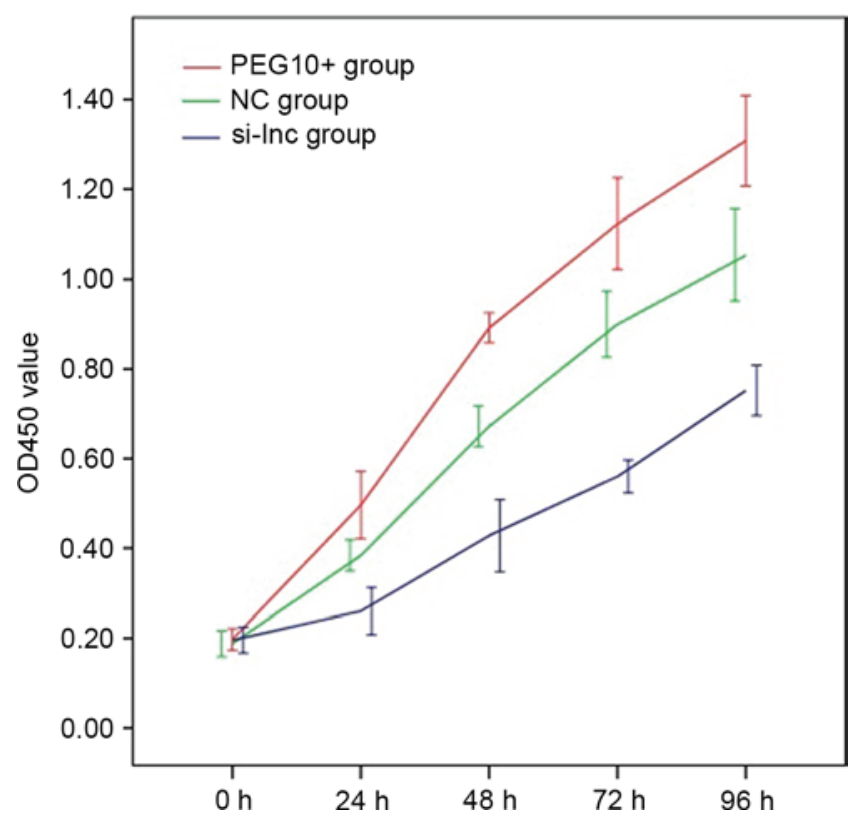

Figure 3. Mean $\mathrm{OD}_{450}$ values from replicate cell proliferation assays of PEG10+, NC and si-lncRNA cells. Proliferation values for the PEG10+ group were significantly higher compared with those of the $\mathrm{NC}$ group at all time points $(\mathrm{P}<0.05)$, while values for the si-lnc group were significantly decreased at the same time points compared with the PEG10+ and $\mathrm{NC}$ groups $(\mathrm{P}<0.05)$. OD, optical density; lnc, long noncoding; PEG10, paternally expressed 10; si-lnc, silencer lncRNA; NC, negative control.

downregulation of lncRNA PEG10 dramatically decreased the migration ability of $\mathrm{FaDu}$ cells.

\section{Discussion}

In humans, $\sim 70 \%$ of the genome is transcribed to generate a range of noncoding RNAs (22). Based on transcript size, noncoding RNAs are classified into small noncoding RNAs (<200 nt) and lncRNAs (>200 nt). Small noncoding RNAs,

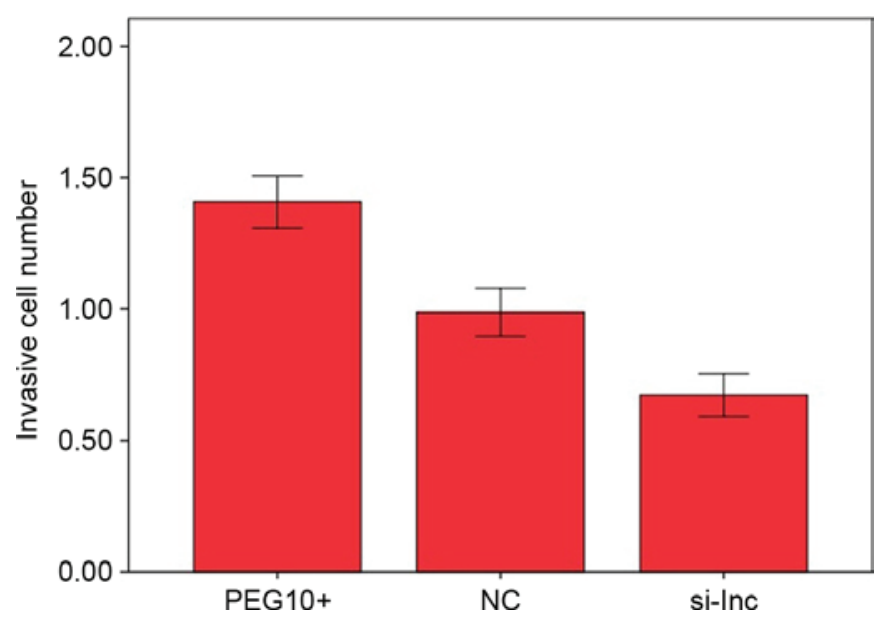

Figure 4. Means of cell numbers penetrating the Transwell membranes in the 3 experimental groups in FaDu cells. The number of invading cells was significantly increased in the PEG10+ group compared with the NC group $(\mathrm{P}<0.05)$. By contrast, the number of invading cells in the si-lnc group was significantly reduced compared with the corresponding numbers in the PEG10+ and NC groups $(\mathrm{P}<0.05)$. 1nc, long noncoding; PEG10, paternally expressed 10; si-lnc, silencer lncRNA; NC, negative control.

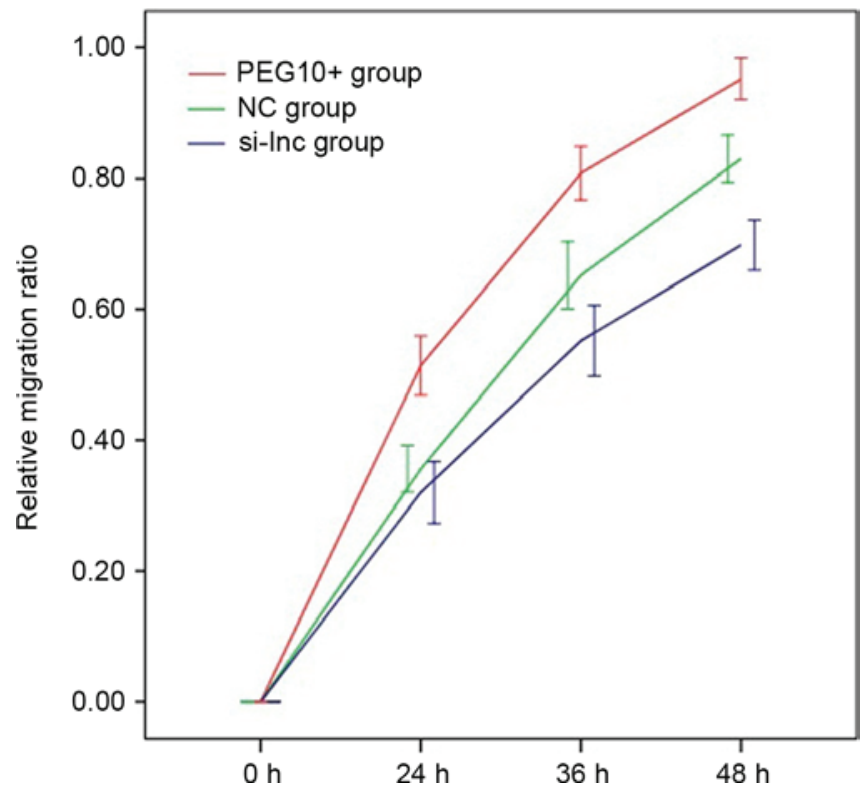

Figure 5. Mean relative migration ratios for the 3 experimental groups of $\mathrm{FaDu}$ cells. The relative migration ratio of FaDu cells in the PEG10+ group was significantly increased compared with the ratios in the $\mathrm{NC}$ and si-lnc groups at each time point $(\mathrm{P}<0.05)$. Similarly, the relative migration ratio of FaDu cells in the NC group was significantly increased compared with the ratio in the si-lnc group at 36 and $48 \mathrm{~h}(\mathrm{P}<0.05)$, but the difference was not significant at $24 \mathrm{~h}$. lnc, long noncoding; PEG10, paternally expressed 10; si-lnc, silencer lncRNA; NC, negative control.

particularly miRNAs, are well characterized as post-transcriptional regulators of mRNAs and have established roles in cancer $(23,24)$. IncRNAs remain poorly characterized, but evidence for their importance and functionality has increased in previous years. Due to their numerous structural and biochemical characteristics, IncRNAs are implicated in a diverse range of functions, including nuclear architecture, immune surveillance, imprinting, epigenetic regulation, cellular trafficking, splicing and pluripotency of embryonic stem cells. IncRNAs 
may regulate gene expression at a number of levels, including chromatin modification, transcription, splicing, translation, post-transcriptional regulation, processing of small RNAS and other important functions $(25,26)$. They may affect and regulate the cell cycle, proliferation, differentiation and apoptosis. Previous studies provide evidence that lncRNAs are also involved in cancer development and the maintenance of tumorigenesis (25), and serve important roles in modulating the proliferation, invasion and metastasis of tumors (27). Previously, dysregulation of lncRNAs has been detected in numerous types of cancer, including breast cancer, hepatocellular carcinoma, melanoma, bladder and prostate cancer (12). Furthermore, the role of certain lncRNAs in cancer, including HOX transcript antisense RNA, metastasis associated lung adenocarcinoma transcript 1 and taurine up-regulated 1 (28-30), has been previously elucidated.

HSCC is one of the most prevalent types of aggressive head and neck malignancy. The most important clinical characteristic of this cancer is its tendency to invade adjacent structures and lymph node metastasis (31). However, despite previous investigation, the underlying mechanisms controlling invasion and metastasis of HSCC remain to be elucidated. The modulatory functions of lncRNAs in HSCC remain to be fully understood. Therefore, the present study investigated the effect of lncRNA PEG10 on proliferation, invasion and metastasis in HSCC.

In a previous esophageal cancer study (18), PEG10 was indicated to regulate proliferation, invasion and metastasis of esophageal cancer cells. In the present study, the expression levels of PEG10 in tumor tissues and normal para-carcinoma tissues in HSCC were measured and demonstrated that there were increased levels in the cancerous tissue. This indicates that PEG10 is associated with HSCC and may possibly participate in the development and carcinogenesis of HSCC. In the present study, the association between PEG10 expression and clinicopathological characteristics in 56 eligible patients exhibited a marked association between PEG10 expression in HSCC tumor tissues and primary tumor size, local lymph node status and TNM stage. These results suggest that overexpression of 1ncRNA PEG10 in tumor tissues promotes the proliferation, invasion and local lymph node metastasis of HSCC, supporting the hypothesis of the present study regarding the role of PEG10 in cancer, and providing a basis for further in vitro experimental studies using the HSCC FaDu cell line.

In a series of in vitro experiments, PEG10 levels were manipulated in transfected FaDu cells and it was identified that increased expression of PEG10 enhanced the proliferation, invasion and migration of $\mathrm{FaDu}$ cells. These results suggest that an overexpression of IncRNA PEG10 may promote proliferation, invasion and metastasis of HSCC cells, in accordance with the association between PEG10 expression and clinicopathological characteristics. Therefore, results from clinical and in vitro approaches support the conclusion that lncRNA PEG10 is involved in HSCC.

There have been a small number of studies regarding the potential mechanisms underlying the ability of PEG10 to promote proliferation, invasion and metastasis of HSCC cells. Zang et al (18) suggested that lncRNA PEG10 may modulate these functions by controlling cell cycle distribution. As for other IncRNAs, certain studies have indicated that lncRNAs may regulate cell proliferation, invasion and metastasis by modulating downstream protein expression, cell cycle arrest and apoptosis $(18,32)$. As lncRNAs may regulate gene expression at transcriptional and post-transcriptional levels $(12,24,25)$, it has been difficult to demonstrate the exact underlying mechanism by which PEG10 promotes proliferation, invasion and metastasis of HSCC cells without systematic studies.

In conclusion, the present study demonstrated that lncRNA PEG10 was upregulated in HSCC and that an overexpression of lncRNA PEG10 promoted proliferation, invasion and migration of the FaDu HSCC cell line. These data suggest that IncRNA PEG10 may be a effective therapeutic target in hypopharyngeal carcinoma therapy and that mechanisms underlying its effect should be further investigated.

\section{Acknowledgements}

The present study was supported by the National Science Foundation of China (grant no. 81102019), the Natural Science Foundation of Shandong Province (grant no. 2012BSE27043) and the Medicine and Health Science Technology Development Project of Shandong Province (grant no. 2014WS0422).

\section{References}

1. Davies L and Welch HG: Epidemiology of head and neck cancer in the United States. Otolaryngol Head Neck Surg 135: 451-457, 2006.

2. Smith RB, Apostolakis LW, Karnell LH, Koch BB, Robinson RA, Zhen W, Menck HR and Hoffman HT: National cancer data base report on osteosarcoma of the head and neck. Cancer 98: $1670-1680,2003$

3. Hoffman HT, Karnell LH, Shah JP, Ariyan S, Brown GS, Fee WE, Glass AG, Goepfert H, Ossoff RH and Fremgen AM: Hypopharyngeal cancer patient care evaluation. Laryngoscope 107: 1005-1017, 1997.

4. Bova R, Goh R, Poulson M and Coman WB: Total pharyngolaryngectomy for squamous cell carcinoma of hypopharynx: A review. Laryngoscope 115: 864-869, 2005.

5. Edge SB and Compton CC: The American Joint Committee on Cancer: The 7th edition of the AJCC cancer staging manual and the future of TNM. Ann Surg Oncol 17: 1471-1474, 2010.

6. Elias MM, Hilgers FJ, Keus RB, Gregor RT, Hart AA and Balm AJ: Carcinoma of the pyriform sinus: A retrospective analysis of treatment results over a 20 -year period. Clin Otolaryngol Allied Sci 20: 249-253, 1995.

7. Wahlberg PC, Andersson KE, Biörklund AT and Möller TR: Carcinoma of the hypopharynx: Analysis of incidence and survival in Sweden over a 30-year period. Head Neck 20: 714-719, 1998.

8. Kurokawa R: Long noncoding RNA as a regulator for transcription. Prog Mol Subcell Biol 51: 29-41, 2011.

9. Walsh AL, Tuzova AV, Bolton EM, Lynch TH and Perry AS: Long noncoding RNAs and prostate carcinogenesis: The missing 'linc'? Trends Mol Med 20: 428-436, 2014.

10. Wapinski $\mathrm{O}$ and Chang HY: Long noncoding RNAs and human disease. Trends Cell Biol 21: 354-361, 2011.

11. Prensner JR and Chinnaiyan AM: The emergence of lncRNAs in cancer biology. Cancer Discov 1: 391-407, 2011.

12. Gutschner T and Diederichs S: The hallmarks of cancer: A long non-coding RNA point of view. RNA Biol 9: 703-719, 2012.

13. Yarmishyn AA and Kurochkin IV: Long noncoding RNAs: A potential novel class of cancer biomarkers. Front Genet 6: 145, 2015.

14. Ono R, Kobayashi S, Wagatsuma H, Aisaka K, Kohda T, Kaneko-Ishino $\mathrm{T}$ and Ishino F: A retrotransposonderived gene, PEG10, is a novel imprinted gene located on human chromosome 7q21. Genomics 73: 232-237, 2001

15. Okabe H, Satoh S, Furukawa Y, Kato T, Hasegawa S, Nakajima Y, Yamaoka Y and Nakamura Y: Involvement of PEG10 in human hepatocellular carcinogenesis through interaction with SIAH1. Cancer Res 63: 3043-3048, 2003. 
16. Kainz B, Shehata M, Bilban M, Kienle D, Heintel D, Krömer-Holzinger E,Le T,Kröber A, Heller G, Schwarzinger I, et al: Overexpression of the paternally expressed gene 10 (PEG10) from the imprinted locus on chromosome $7 \mathrm{q} 21$ in high-risk B-cell chronic lymphocytic leukemia. Int J Cancer 121: 1984-1993, 2007.

17. Peng W, Fan H, Wu G, Wu J and Feng J: Upregulation of long noncoding RNA PEG10 associates with poor prognosis in diffuse large B cell lymphoma with facilitating tumorigenicity. Clin Exp Med 16: 177-182, 2016.

18. Zang W, Wang T, Huang J, Li M, Wang Y, Du Y, Chen X and Zhao G: Long noncoding RNA PEG10 regulates proliferation and invasion of esophageal cancer cells. Cancer Gene Ther 22: 138-144, 2015.

19. Hu C, Xiong J, Zhang L, Huang B, Zhang Q, Li Q, Yang M, Wu Y, Wu Q, Shen Q, et al: PEG10 activation by co-stimulation of CXCR5 and CCR7 essentially contributes to resistance to apoptosis in CD19+CD34+ B cells from patients with B cell lineage acute and chronic lymphocytic leukemia. Cell Mol Immunol 1: 280-294, 2004

20. Livak KJ and Schmittgen TD: Analysis of relative gene expression data using real time quantitative PCR and the 2(-Delta Delta C(T)) method. Methods 25: 402-408, 2001.

21. The 8th edition American Joint Committee on Cancer (AJCC) classification system. Available from: http: //cancerstaging. org/About/Pages/8th-Edition.aspx, 2010.

22. Djebali S, Davis CA, Merkel A, Dobin A, Lassmann T, Mortazavi A, Tanzer A, Lagarde J, Lin W, Schlesinger F, et al: Landscape of transcription in human cells. Nature 489: 101-108, 2012.

23. Fabian MR and Sonenberg N: The mechanics of miRNA-mediated gene silencing: A look under the hood of miRISC. Nat Struct Mol Biol 19: 586-593, 2012.

24. Kong YW, Ferland-McCollough D, Jackson TJ and Bushell M: microRNAs in cancer management. Lancet Oncol 13: e249-e258, 2012.

25. Gibb EA, Vucic EA, Enfield KS, Stewart GL, Lonergan KM, Kennett JY, Becker-Santos DD, MacAulay CE, Lam S, Brown CJ and Lam WL: Human cancer long non-coding RNA transcriptomes. PLoS One 6: e25915, 2011.
26. Ma L, Bajic VB and Zhang Z: On the classification of long non-coding RNAs. RNA Biol 10: 924-933, 2013.

27. Gupta RA, Shah N, Wang KC, Kim J, Horlings HM, Wong DJ, Tsai MC, Hung T, Argani P, Rinn JL, et al: Long non-coding RNA HOTAIR reprograms chromatin state to promote cancer metastasis. Nature 464: 1071-1076, 2010.

28. Chen FJ, Sun M, Li SQ, Wu QQ, Ji L, Liu ZL, Liu ZL, Zhou GZ, Cao G, Jin L, et al: Upregulation of the long non-coding RNA HOTAIR promotes esophageal squamous cell carcinoma metastasis and poor prognosis. Mol Carcinog 52: 908-915, 2013.

29. Liu JH, Chen G, Dang YW, Li CJ and Luo DZ: Expression and prognostic significance of 1 ncRNA MALAT-1 in pancreatic cancer tissues. Asian Pac J Cancer Prev 15: 2971-2977, 2014.

30. Zhang Q, Geng PL, Yin P, Wang XL, Jia JP and Yao J: Down-regulation of long non-coding RNA TUG1 inhibits osteosarcoma cell proliferation and promotes apoptosis. Asian Pac J Cancer Prev 14: 2311-2315, 2013.

31. Kleist B, Bankau A, Lorenz G, Jng KA and Poetsch M: Different risk factors in basaloid and common squamous head and neck cancer. Laryngoscope 114: 1063-1068, 2004.

32. Hu L, Wu Y, Tan D, Meng H, Wang K and Bai Y: Up-regulation of long noncoding RNA MALAT-1 contributes to proliferation and metastasis in esophageal squamous cell carcinoma. J Exp Clin Cancer Res 34: 7, 2015. 